\title{
CHUVA DE SEMENTES EM REMANESCENTES FLORESTAIS DE CAMPO VERDE, MT $^{1}$
}

\author{
William Pietro-Souza², Normandes Matos da Silva³ e Érica Pereira de Campos ${ }^{4}$
}

\begin{abstract}
RESUMO - O objetivo deste trabalho consistiu em avaliar sazonalmente a produção de sementes provenientes de fragmentos florestais presentes na zona rural de Campo Verde, MT. Essa caracterização ocorreu em termos de produção de sementes e riqueza de espécies vegetais. Foram selecionados três fragmentos florestais caracterizados como Floresta Estacional Semidecidual. Em cada fragmento, cinco coletores foram instalados e confeccionados com canos de PVC ( $1 \mathrm{~m}^{2}$; malha de náilon de $0,001 \mathrm{~m}$ e $0,15 \mathrm{~m}$ de profundidade do bojo). O material foi coletado mensalmente, cujas sementes foram quantificadas e separadas conforme a síndrome de dispersão, etapa sucessional e forma de vida. Houve a determinação da densidade, frequência absoluta, índice de diversidade e equitabilidade. Ao todo, foram obtidas 3.622 sementes, pertencentes a 74 táxons. Maiores densidades de sementes foram observadas durante os meses de setembro, outubro e novembro. As lianas Gouania sp., Fridericia speciosa, Heteropterys sp. e Distictella sp. responderam com 55,95\% do total de sementes aportadas. Das espécies que compuseram a chuva de sementes, $74 \%$ não são dispersas pelo vento. Todavia, quando se verificou a quantidade de diásporos coletados, formas dispersas pelo vento foram predominantes, representando $76 \%$ do total. Citam-se como táxons arbóreos importantes para a recomposição florestal na região de Campo Verde, situada no Sudeste de Mato Grosso: Tachigali rubiginosa, Siparuna guianensis, Nectandra sp., Cordia alliodora, Alibertia sp., Terminalia brasiliensis e Myrcia sp. Essas espécies devem ser alvo de estudos mais específicos relacionados ao seu potencial para recuperação de ambientes degradados, considerando-se as Áreas de Preservação Permanente e Reservas Legais.
\end{abstract}

Palavras-chave: Nucleação; Florestas Estacionais Semideciduais; Recuperação de Áreas Degradadas.

\section{SEED RAIN IN REMAINING FOREST FRAGMENTS IN CAMPO VERDE, MT}

\begin{abstract}
The objective of this study consists in evaluating seasonally the seeds production from forest fragments located in rural zone of Campo Verde, MT. This characterization occurred in terms of seed production and plant species richness. Three forest fragments characterized as semidecidual stational forest were selected. In each fragment five collectors were installed and made with PVC pipes $\left(1 \mathrm{~m}^{2}\right.$; nylon mesh of $0.001 \mathrm{~m}$ and $0.15 \mathrm{~m}$ depth of the bulge). The material was monthly collected, and the seeds were quantified, and separated according to the sort of dispersal, successional stage and form of life. It was determined the density, absolute frequency, diversity index and equitability. Altogether 3,622 seeds were collected, belonging to 74 taxa. The highest densities of seeds were observed during the months of September, October and November. Lianas Gouania sp., Fridericia speciosa, Heteropterys sp. and Distictella sp. responded with 55.95\% of total collected seeds. From all the species that composed the seed rain, 74\% are not dispersed by wind. However, when the amount of diaspores collected was checked, forms dispersed by wind were predominant, representing $76 \%$ of total. It may be cited as important arboreal taxons for reforestation in the region of Campo Verde, located at southeast of Mato Grosso: Tachigali rubiginosa, Siparuna guianensis, Nectandra sp., Cordia alliodora, Alibertia sp., Terminalia brasiliensis and Myrcia sp. These species should be targeted for more specific studies related to their potential for recovery of degraded environments, considering permanent preservation areas and legal reserves.
\end{abstract}

Keywords: Nucleation; Semidecidual Stational Forests; Recovery of degraded areas.

\footnotetext{
${ }^{1}$ Recebido em 09.02.2013 aceito para publicação em 27.05.2014.

${ }^{2}$ Programa de Pós-Graduação em Biotecnologia e Biodiversidade, Rede Pró-Centro Oeste/UFMT, Brasil. E-mail: <william_pietro@hotmail.com>.

${ }^{3}$ Universidade Federal de Mato Grosso, UFMT, Instituto de Ciências Agrárias e Tecnológicas - ICAT, Brasil. E-mail: $<$ normandes32@gmail.com>.

${ }^{4}$ Universidade Federal de Mato Grosso, UFMT, Brasil. E-mail: <camposep@hotmail.com>.
} 


\section{INTRODUÇÃO}

Áreas de Preservação Permanentes, em especial matas ciliares, são locais frágeis dos pontos de vista físico e biótico. Essas formações prestam serviços ambientais importantes, como proteção dos recursos hídricos, do solo, da estabilidade geológica, da biodiversidade, do fluxo gênico de flora e da fauna, além de garantir o bem-estar das populações humanas (BRASIL, 1965).

Em florestas tropicais, a regeneração está intimamente ligada ao recrutamento de novos indivíduos, decorrente, sobretudo, da entrada de sementes no ecossistema (PENHALBER; MANTOVANI, 1997). Esse mecanismo funcional é determinado por meio da chuva de sementes.

O estudo da chuva de sementes permite conhecer padrões fenológicos das espécies vegetais locais e o padrão de queda de sementes no solo, considerandose sua forma de dispersão e formas de vida (CAMPOS et al., 2009).

Pesquisas relacionadas ao conhecimento do padrão da chuva de sementes proporcionam informações valiosas sobre abundância, distribuição espacial, densidade e riqueza de espécies (GROMBONE-GUARANTINI; RODRIGUES, 2002), além de evidenciarem padrões de entrada de propágulos no ecossistema.

A entrada desses elementos influencia o processo de regeneração natural da vegetação, com consequência no fechamento de clareiras e, até mesmo, na regeneração de áreas degradadas (CLARK; POULSEN, 2001; GROMBONE-GUARATINI; RODRIGUES, 2002; CAMPOS; SOUZA, 2003).

A transposição da chuva de sementes é compreendida como estratégia de recuperação de área degradada, cuja distribuição de coletores em áreas vegetadas próximas aos locais que deverão ser recuperados permitirá a coleta de sementes de diferentes espécies, com variabilidade genética (REIS et al., 2010).

No Brasil, a maioria dos trabalhos sobre chuva de sementes concentra-se na Região Sudeste, especialmente em diferentes tipologias da Floresta Atlântica (PENHALBER; MANTOVANI, 1997; GROMBONE-GUARATINI; RODRIGUES, 2002; ARAÚJO et al., 2004; PIVELLO et al., 2006; JESUS et al., 2012).

Revista Árvore, Viçosa-MG, v.38, n.4, p.689-698, 2014

Revista Árvore, Viçosa-MG, v.38, n.4, p.689-698, 2014
Informações sobre chuva de sementes em florestas na região Sudeste de Mato Grosso são escassas. Diante disso, este trabalho procurou avaliar sazonalmente a chuva de sementes em trechos de remanescentes florestais nativos situados na zona rural de Campo Verde, MT, considerando-se como elemento de análise da chuva de sementes em termos de densidade, frequência absoluta, diversidade e equitabilidade.

\section{MATERIAL E MÉTODOS}

\section{1. Área de estudo}

O estudo foi conduzido na comunidade rural Capim Branco, situada a $20 \mathrm{~km}$ do perímetro urbano do Município de Campo Verde, MT (Figura 1), mais precisamente em três fragmentos situados em trechos considerados Áreas de Preservação Permanente, caracterizados como Floresta Estacional Semidecidual. Essas formações vegetais situam-se sob Neossolos Quartzarênicos, associado à Latossolo Vermelho-Escuro álico (SEPLAN, 2001).

Fonte: SEMA, 2012 (com adaptações). Source: SEMA, 2012 (adapted).

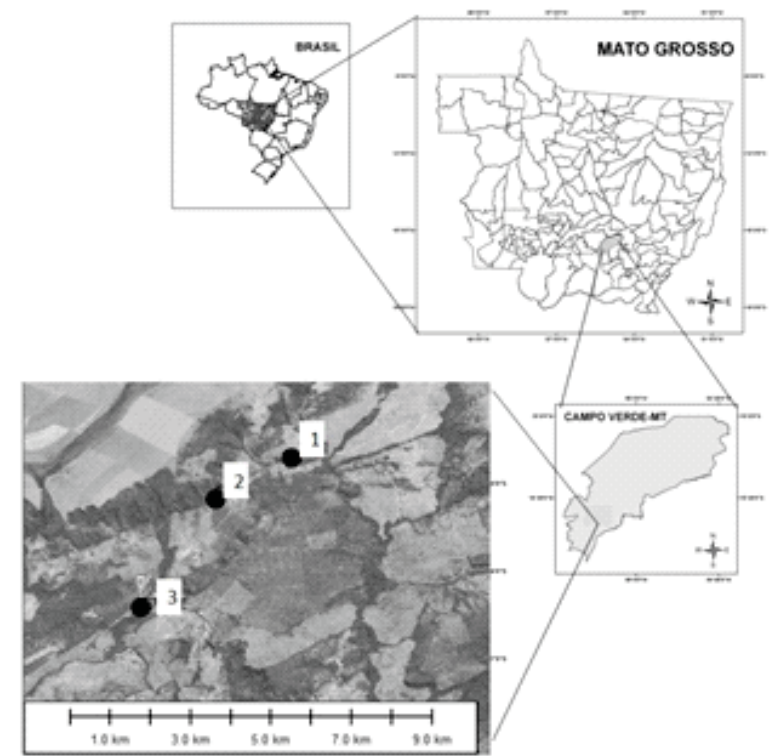

Figura 1 - Localização dos sítios de coleta (1), (2) e (3) situados em remanescentes de Floresta Estacional Semidecidual, no Município de Campo Verde, MT.

Figure 1 - Location of collecting sites (1), (2) and (3) from semidecidual stational forest fragments, Campo Verde, MT. 
O clima é do tipo tropical quente e subúmido, com cinco meses de seca (maio-setembro) e período chuvoso (outubro-abril). A precipitação média anual é de 1.750 $\mathrm{mm}$, com intensidade máxima entre dezembro-fevereiro e temperatura média anual de $24{ }^{\circ} \mathrm{C}$ (INMET, 2014).

\subsection{Chuva de sementes}

Foram instalados 15 coletores construídos com cano de PVC ( $1 \mathrm{~m}^{2}$; malha de náilon de 0,001 m e 0,15 $\mathrm{m}$ de profundidade do bojo), suspensos a 0,9 $\mathrm{m}$ do solo. Os coletores foram instalados aleatoriamente no interior dos fragmentos, sendo cinco em cada local. O critério aleatorizado ocorreu a partir da inspeção visual dos ambientes estudados e da demarcação dos locais de instalação dos coletores, independentemente se estes ficariam no setor de borda ou no interior dos fragmentos.

O material depositado foi recolhido mensalmente entre os meses de novembro (2011) e outubro (2012). As sementes foram separadas dos outros materiais (frutos, galhos, folhas, flores, insetos etc.) e classificadas conforme: (1) o modo de dispersão (vento e não vento), segundo Marimon e Felfili (2006); (2) estádio sucessional (pioneiras, secundárias, climácicas), conforme Budowsky (1965); e (3) forma de vida (arbóreas, arbustos, herbáceas e lianas), de acordo com Ramirez (1993).

Determinaram-se a densidade (DA) e frequência absolutas (FA), calculadas para cada táxon, inclusive para os indeterminados, sendo $\mathrm{D}=\mathrm{n} / \mathrm{A}$ e $\mathrm{F}=100 \times(\mathrm{p} / \mathrm{P})$, em que $\mathrm{n}=$ número de sementes de cada espécie, $\mathrm{A}$ = área amostrada $\left(\mathrm{m}^{2}\right), \mathrm{p}=$ número de amostras com cada espécie e $\mathrm{P}$ = número total de amostras (MUELLERDOMBOIS; ELLENBERG, 1974). Calcularam-se, ainda, os índices de Shannon-Weaver (H') e equitabilidade de Pielou (J') (BROWER; ZAR, 1984); em ambas as análises, utilizou-se o Programa Past, version 1.79 (HAMMER et al., 2001).

Os dados foram submetidos à análise de variância a 5\% de probabilidade. Aos resultados significativos, aplicou-se o teste de médias (Scott-Knott), por meio do Programa SISVAR (FERREIRA, 2008).

\section{RESULTADOS}

Dos 74 táxons coletados, 11 foram identificados em nível específico, 16 em nível de gênero, 15 em nível de família e 32 não foram identificados. Conforme o hábito de vida, 21 táxons foram classificados como árvores e seis como lianas. Em relação aos estágios sucessionais, seis táxons pertenceram ao grupo das pioneiras, seis foram secundárias iniciais e dois secundárias tardias (Tabela 1). As famílias com maiores números de espécies foram Fabaceae (7), Bignoniaceae (5) e Euphorbiaceae (4), conforme mostrado na Tabela 1.

Foram contabilizadas no decorrer dos 12 meses de estudos 3.622 sementes, distribuídas em 19 famílias botânicas. As famílias que mais contribuíram para o total de sementes foram: Rhamnaceae (34\%), Bignoniaceae (19\%) e Fabaceae (10\%) (Tabela 1). O índice de diversidade de Shannon-Weaver $(\mathrm{H})$ e o de equitabilidade ( $\mathrm{J}$ ) da chuva de sementes obtidos neste estudo foram de 2,56 nats ind ${ }^{-1}$ e 0,60 , respectivamente.

A produção da chuva de sementes apresentou diferenças sazonais significativas $(\mathrm{P}<0,001)$, para densidade de sementes e riqueza de espécies (Figura 2AB), com tendência a maiores valores durante os meses finais do período de seca (setembro) e iniciais do período chuvoso (outubro e novembro).

Outubro apresentou a maior densidade de sementes (63,13 sementes. $\left.\mathrm{m}^{-2}\right)$. Nesse mês, a contribuição de Gouania sp. e Tachigali rubiginosa foram as mais representativas (23,7 e 17,3 sementes.m²; Figura 2A e Tabela 1). Verificou-se baixa ocorrência de Gouania sp. (13\%) entre os coletores. Já Tachigali rubiginosa esteve presente em $80 \%$ dos coletores. Essas espécies foram responsáveis por $59,2 \%$ das sementes aportadas nesse período.

Em setembro, a densidade de sementes foi de 51,40 sementes. $\mathrm{m}^{-2}$, com contribuição importante por parte de Gouania sp. (16,1 sementes. $\mathrm{m}^{-2}$ ) e Fridericia speciosa (13 sementes. m-2; Figura 2A e Tabela 1) e ocorrência de 13,3 e $86,7 \%$, respectivamente, para essas espécies. Somando as sementes produzidas por essas espécies, a representatividade foi de $56,7 \%$ em relação ao montante de sementes coletas nesse período.

Em novembro, a densidade de sementes foi de 39,5 sementes. ${ }^{-2}$, sendo Fridericia speciosa $(11,1$ sementes. $\mathrm{m}^{-2}$ ), Gouania sp. e Heteropterys sp. (ambas com 10,2 sementes. $\mathrm{m}^{-2}$ ) as mais representativas (Figura 2A e Tabela 1); Fridericia speciosa ocorreu em 66,7\%, Heteropteys sp. em $60 \%$ e Gouania sp. em $20 \%$ dos coletores. Juntas, essas espécies representaram 79,8\% do total de sementes aportadas nesse período. As menores densidades de sementes foram verificadas em junho e maio (respectivamente 2,5 e 3,9 sementes. $\mathrm{m}^{-2}$ ).

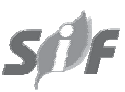

Revista Árvore, Viçosa-MG, v.38, n.4, p.689-698, 2014 


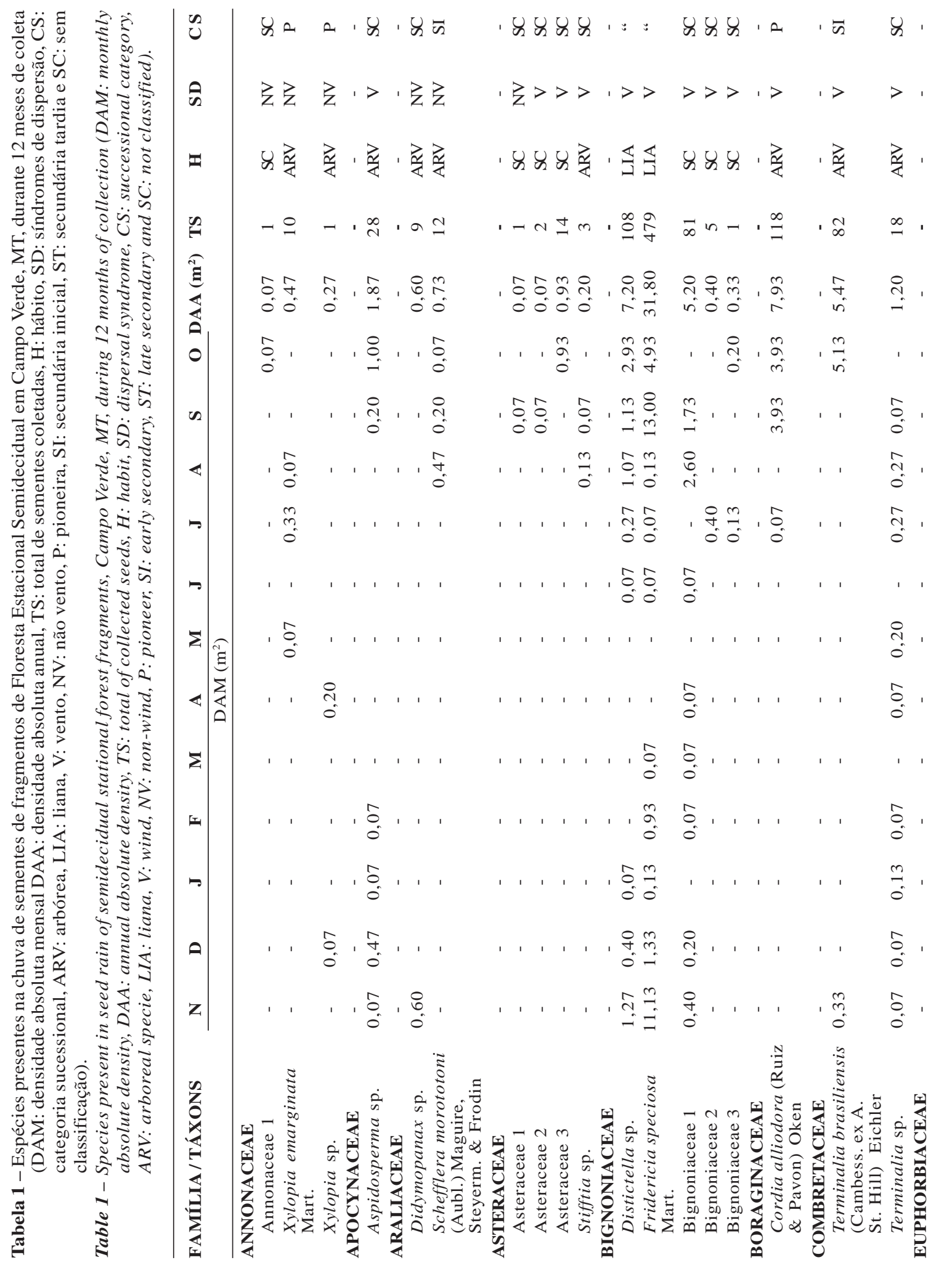




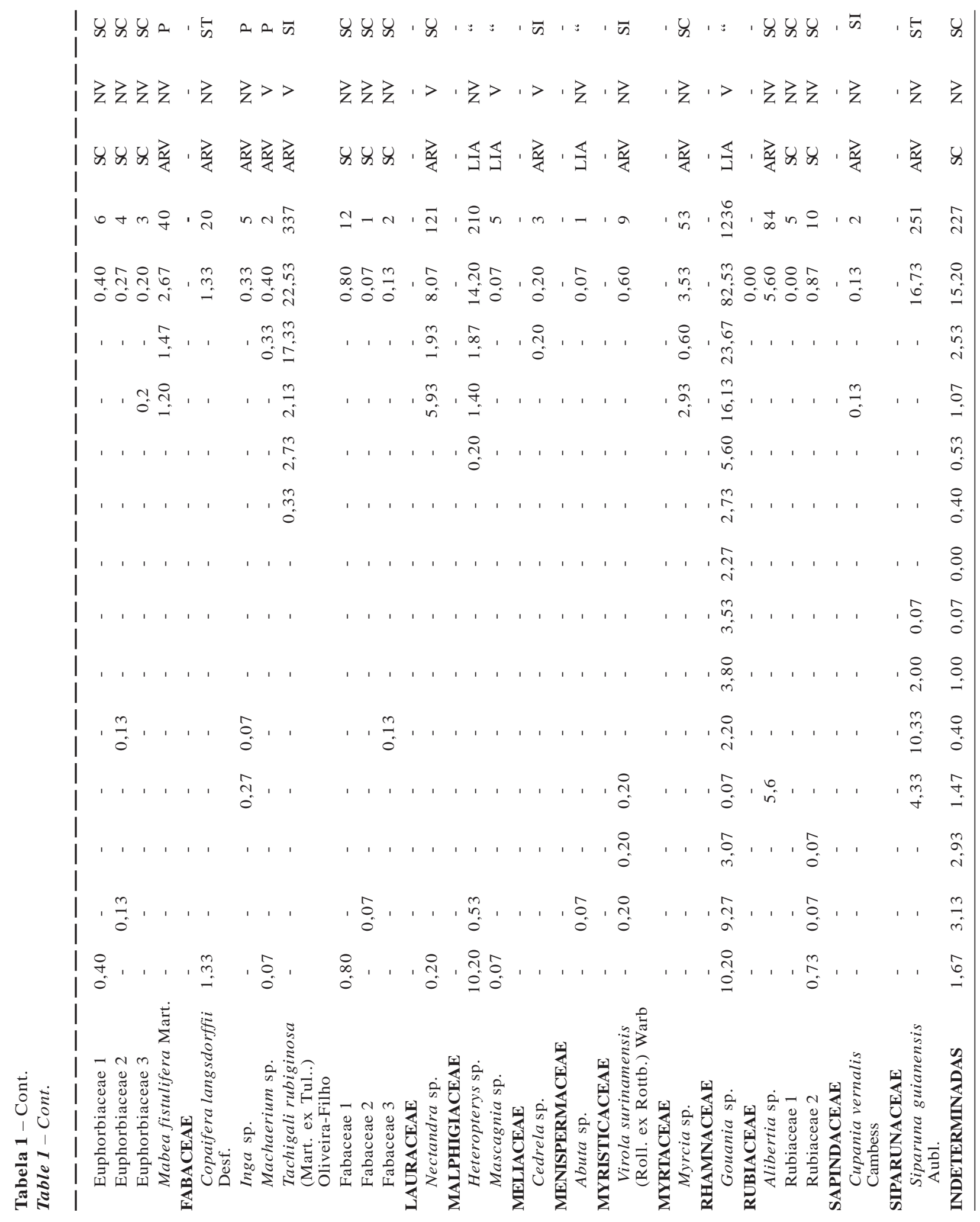


A Figura 2B evidencia a riqueza de espécies, em que os meses de setembro e outubro são marcados pelos maiores valores (25 e 22 táxons, respectivamente). Já os menores valores foram obtidos durante os meses de junho e maio (4 e 5 táxons, respectivamente).

Conforme a síndrome de dispersão, do total de diásporos coletados, $76 \%$ foram dispersos pelo vento e $24 \%$ por outros mecanismos (não vento), como zoocóricas ou autocóricas (Tabela 1). Quando se considera o número de táxons, verifica-se um padrão contrário, com maior proporção de espécies que não utilizam o vento (74\%), em comparação com as espécies dispersas pelo vento (26\%).

A chuva de sementes apresentou picos de dispersão de sementes pelo vento, principalmente durante os meses de seca (maio a setembro) e os meses iniciais do período de chuva na região (outubro, novembro e dezembro). Já as espécies cuja propagação independe do vento (não vento) foram abundantes durante os meses de fevereiro e março (Figura 3).

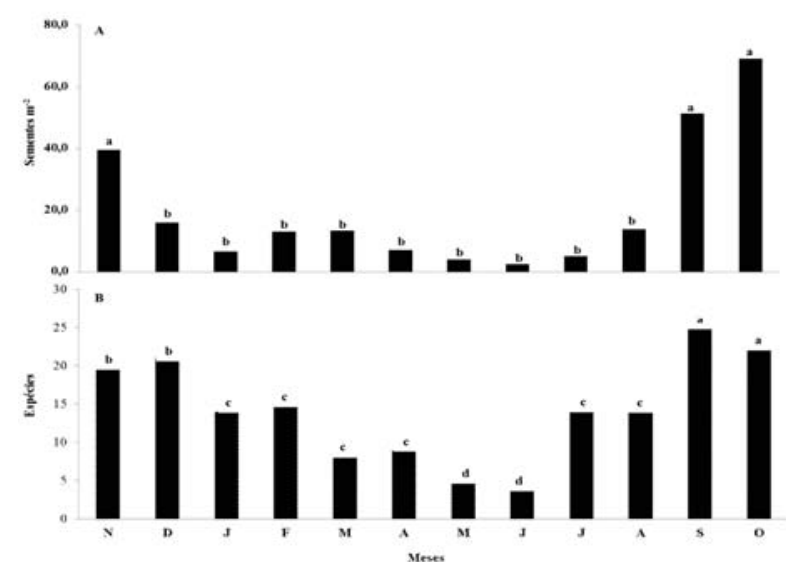

Figura 2 - Densidade mensal de sementes (A) e riqueza de espécies (B) oriundas da chuva de sementes ao longo do ano em fragmentos sob domínio de Floresta Estacional Semidecidual, no Município de Campo Verde, MT (Valores seguidos da mesma letra minúscula não diferem entre si, pelo teste de Scott-Knott a $5 \%$ de probabilidade).

Figure 2 - Seed monthly density (A) and species richness (B) derived from the seed rain throughout the year in fragments of semidecidual stational forest, Campo Verde-MT (Values followed by the same lowercase letter do not differ by Scott-Knott test at $5 \%$ probability).

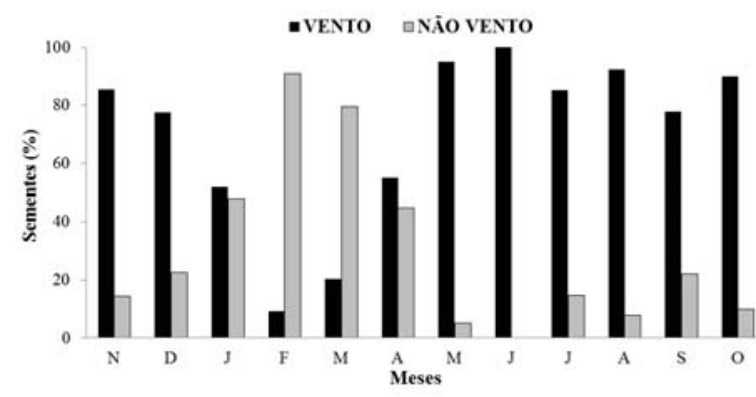

Figura 3 - Formas de dispersão mensais de sementes oriundas da chuva de sementes da Floresta Estacional Semidecidual, no Município de Campo Verde, MT.

Figure 3-Forms of monthly dispersion of seeds originating from seed rain from semidecidual stational forest in Campo Verde, MT.

\section{DISCUSSÃO}

A abundância de sementes (3.622 sementes) foi baixa em comparação com a de estudos realizados por Campos et al. (2009) em Floresta Estacional Semidecidual, no Município de Viçosa, MG; por Jesus et al. (2012) e Pivello et al. (2006), em Floresta Ombrófila Densa Montana, em São Paulo; e por Penhalber e Mantovani (1997), em Floresta Secundária de Transição entre Floresta Ombrófila e Estacional, na região metropolitana de São Paulo.

A densidade média anual nos três fragmentos foi de 241,5 sementes. $\mathrm{m}^{-2}$, números acima dos obtidos por Campos et al. (2009) durante o primeiro ano (113,9 sementes. $\mathrm{m}^{-2}$ ) de estudo. Porém, no segundo ano, o valor da densidade do trabalho citado foi superior (2.603,8 sementes. $\mathrm{m}^{-2}$ ).

Segundo Au et al. (2006), as variações na densidade de sementes provenientes da chuva de sementes, nos variados ambientes, têm relação com inúmeros fatores, como composição e estrutura florística da comunidade, além das atividades de agentes dispersores de sementes. Além disso, há dificuldade em fazer comparações coesas, devido à carência de trabalhos com chuva de sementes em fragmentos florestais presentes na região abrangida pela área de estudo e, ainda, pelo fato de haver diferenças metodológicas entre os estudos (GROMBONEGUARATINI; RODRIGUES, 2002). O valor total de táxons encontrados (74) foi superior ao obtido por Campos et al. (2009), que registraram 43 espécies em Floresta Estacional Semidecidual. Pivello et al. (2006) verificaram a presença de 61 espécies ou morfoespécies em Floresta 
Ombrófila Densa Montana. Penhalber e Mantovani (1997) apontaram a presença de 90 espécies na composição da chuva de sementes em Floresta Secundária de Transição.

O índice de diversidade de Shannon-Weaver e de equitabilidade da chuva de (2,56 nats ind ${ }^{-1}$ e 0,60 , respectivamente) é similar aos resultados obtidos por Duarte (2011) em vegetação ciliar classificada como Floresta Estacional Semidecidual, na região do baixo rio São Francisco (2,3 nats ind $\left.{ }^{-1}\right)$, e equitabilidade em torno de 0,53. Já Lagos e Marimon (2012) encontraram valores superiores de diversidade (3,14 a 3,62 nats ind. ${ }^{-1}$ ) em três porções da floresta do Córrego Bacaba, no Município de Nova Xavantina, em Mato Grosso.

O valor reduzido de equitabilidade pode ser explicado pela grande diferença encontrada nos valores de abundâncias das espécies, uma vez que as três espécies mais abundantes (Gouania sp., Fridericia speciosa e Tachigali rubiginosa) representaram, sozinhas, cerca de $57 \%$ do valor total de sementes amostradas. Segundo Vieira e Gandolfi (2006), baixos valores de equitabilidade e, consequentemente, de diversidade mostram que há predomínio de determinadas espécies.

As espécies Fridericia speciosa, Heteropteys sp., Gouania sp. e Tachigali rubiginosa foram as mais representativas para o total de sementes durante os meses de maior produção (setembro, outubro e novembro), sendo essas espécies anemocóricas. Penhalber e Mantovani (1997) explicaram que, pelo tamanho reduzido e leve, as sementes anemocóricas são facilmente derrubadas pela chuva, apresentando picos de dispersão no início do período chuvoso.

A maior produção de sementes foi obtida no final do período seco e início da fase chuvosa, resultados também reportados em outras formações florestais (PENHALBER; MANTOVANI, 1997; GROMBRONEGUARATINI; RODRIGUES, 2002; ARAUJO et al., 2004; VIEIRA; GANDOLFI, 2006; LAGOS; MARIMON, 2012).

A baixa produção de sementes ocorreu nos meses de junho e julho, mas resultados contrários foram obtidos por Vieira e Gandolfi (2006), que observaram aumento na deposição de sementes no mês de julho em florestas sob processo de restauração. Segundo esses autores, a deposição de sementes nesse período foi favorecida pela ocorrência de ventos fortes na região (Município de Iracemápolis, SP), e essa intempérie contribuiu para a deposição de propágulos. Ao longo da execução desta pesquisa, não houve registro ou evidência de ocorrência de ventos fortes na área estudada.

Setembro e outubro apresentaram as maiores densidades de sementes (Figura 2AB) e números de espécies (Figura 3). Já os meses de maio e junho foram marcados por reduzida densidade de sementes e riqueza. O aumento e decréscimo de propágulos coletados coincidem com o maior e menor número de espécies. Penhalber e Mantovani (1997) e Vieira e Gandolfi (2006) verificaram esse padrão, apontando relação positiva entre riqueza de espécies e densidade de propágulos presentes na chuva de sementes, ao longo do período de coleta.

De maneira geral, as lianas Gauania sp., Fridericia speciosa, Heteropterys sp. e Distictella sp. responderam, sozinhas, com 55,95\% do total de sementes aportadas. Penhalber e Mantovani (1997) verificaram que 12 espécies de lianas responderam por quase $50 \%$ do total da chuva de sementes, o que é justificado pela ocupação do dossel das árvores por lianas, além da ampla ocorrência desse grupo de vegetal em Florestas Estacionais Semideciduais (LEITÃO FILHO, 1995).

Em relação à síndrome de dispersão, ocorreu dominância de espécies que não utilizam o vento para sua propagação (não vento). Clark e Poulsen (2001), em estudo em uma Floresta Tropical localizada em Camarões, na África, verificaram que a dispersão anemocórica representou a menor quantidade de espécies (16\%), diante daquelas dispersadas por vertebrados.

Dispersão zoocórica (não vento) em florestas tropicais é a síndrome de mais de 75\% das espécies vegetais (HOWE; SMALLWOOD, 1982). Resultados similares foram obtidos por Stefanello et al. (2009) em trecho de vegetação ciliar (Floresta Estacional Semidecidual), no meio e na foz do rio Pindaíba, em Mato Grosso, onde 85,7 e 77,5\% das espécies desses ambientes não utilizam o vento como forma de propagação (zoocórica). Altas proporções de espécies zoocóricas presentes na chuva de sementes são indícios de ambientes conservados (TABARELLI; PERES, 2002; MELO et al., 2010; URIARTE et al., 2011).

Sementes cuja dispersão independe do vento, como as zoocóricas, são menos representativas na chuva de sementes, tanto em número quanto em densidade (PIVELLO et al., 2006). Esse padrão também foi verificado 
por Clark e Poulsen (2001), cuja dispersão pelo vento contribuiu substancialmente para o montante de sementes coletadas. Ainda segundo esses autores, apesar da concepção comum de que árvores em florestas tropicais dependem, em grande parte, dos vertebrados dispersores de sementes, o vento e mecanismos balísticos podem dispersar maior número de sementes.

Jesus et al. (2012) também verificaram predomínio de diásporos anemocóricos (76,8\%) na composição da chuva de sementes em Floresta Ombrófila Densa Montana. No entanto, em termos de espécies, a dispersão zoocórica contribuiu em maior número.

A sazonalidade de diásporos dispersos pelo vento, no final do período de seca (agosto e setembro) e início do período chuvoso (outubro), está de acordo com outros estudos de chuva de sementes realizados em fragmentos de florestas estacionais (PENHALBER; MANTOVANI, 1997; GROMBONE-GUARATINI; RODRIGUES, 2002; MARIMON; FELFILI, 2006).

Nos meses de fevereiro e março, durante a estação chuvosa, a dipersão de sementes via animal ou autonôma (autocórica) tornou-se predominante. Esse período foi marcado pela abundância de Sipraruna guianensis, cujos propágulos apresentam dispersão zoocórica. Espécies zoocóricas costumam dispersar seus propágulos, principalmente, no meio da estação chuvosa, pois o aumento da umidade e da insolação favorece o amadurecimento de frutos suculentos, tornando-os mais atrativos aos dispersores (GAUTIER-HION, 1990).

Partindo do pressuposto da recuperação de áreas degradadas, a coleta de sementes poderá ser utilizada na recuperação ambiental, por meio da produção de mudas ou semeadura direta no campo, propiciando a formação de núcleos de diversidade (REIS et al., 2010). O conhecimento da composição da chuva de sementes permite selecionar espécies com ocorrência na região e sua posterior recomendação para planos de recuperação de áreas degradadas.

Bechara et al. (2007), utilizando a chuva de sementes como técnica nucleadora, produziram 455 mudas de 39 espécies nativas, em cinco meses de estudo. Segundo Reis et al. (1999), a coleta mensal de sementes provenientes da chuva de sementes permite a contínua produção de mudas de espécies que frutificam em todos os meses do ano, auxiliando a manutenção da fauna na área degradada.

\section{CONCLUSÕES}

Nas condições utilizadas neste trabalho, as maiores densidades de sementes e riqueza de espécies foram obtidas durante os meses de setembro, outubro e novembro.

Há prevalência de espécies que não utilizam o vento para dispersão. Porém, em termos de número de propágulos coletados, a dispersão pelo vento foi superior nas espécies estudas.

Os resultados da pesquisa indicaram que os táxons considerados estratégicos para a recomposição florestal de áreas degradadas na região de Campo Verde foram Tachigali rubiginosa, Siparuna guianensis, Nectandra sp., Cordia alliodora, Alibertia sp., Terminalia brasiliensis e Myrcia sp.

Essas espécies devem ser alvo de estudos mais específicos relacionados ao potencial delas para recuperação de ambientes degradados, considerando-se as Áreas de Preservação Permanente e Reservas Legais.

\section{AGRADECIMENTOS}

À Fundação de Amparo à Pesquisa do Estado de Mato Grosso (FAPEMAT), pela bolsa de mestrado concedida ao primeiro autor; e ao Conselho Nacional de Desenvolvimento Científico e Tecnológico (CNPq), pelo recurso financeiro para a execução do projeto (Processos CNPq n 561923/2010-8 e 310724/2011-2).

\section{REFERÊNCIAS}

ARAÚJO, M. M. et al. Caracterização da chuva de sementes, banco de sementes do solo e banco de plântulas em Floreta Estacional Decidual Ripária, Cachoeira do Sul, RS, Brasil. Scientia

Forestalis, v.66, p.128-141, 2004.

AU, A. Y. Y.; CORLETT, R. T.; HAU, B. C. H. Seed rain into upland plant communities in Hong Kong, China. Plant Ecology, v.186, n.1, p.13-22, 2006.

BRASIL. Lei no 4771, de 15 de setembro de 1965. Institui o novo Código Florestal. Diário

Oficial [da República Federativa do Brasil], Brasília, DF. Seção 1. 1965.

BECHARA, F. C. et al. Unidades Demonstrativas de Restauração Ecológica através de Técnicas Nucleadoras de Biodiversidade. Revista Brasileira de Biociências, v.5, supl.1, p.911, 2007. (Nota científica). 
BROWER, J. E.; ZAR, J. H. Field and laboratory methods for general ecology. Dubuque: W. M. C. Brow, 1984. 226p.

BUDOWISK, G. Distribution of tropical American rain forest species in the light of successional processes. Turrialba, v.15, n.1, p.40-42, 1965.

CAMPOS, E. P. et al. Chuva de sementes em Floresta Estacional Semidecidual em Viçosa, MG, Brasil. Acta Botânica Brasílica, v.23, n.2. p.451-458, 2009.

CAMPOS, J. B.; SOUZA, M. C. Potencial for natural forest regeneration from seed bank in an upper Paraná river floodplain, Brazil. Brazilian Archives of Biology and Technology, v.46, n.4, p. 625-639, 2003.

CLARK, C. J.; POULSEN, J. R. The role of arboreal seed dispersal groups on the seed rain of a lowland tropical forest. Biotropica, v.33, n.4, p.606-620, 2001.

DUARTE, J. M. M. Chuva de sementes e banco de plântulas em um fragmento florestal de vegetação ciliar na região do baixo São Francisco, Sergipe, Brasil. 2011. 93f. Dissertação (Mestrado em Ecologia e Conservação) - Programa de PósGraduação em Ecologia e Conservação, Universidade Federal de Sergipe, Sergipe, 2011.

FERREIRA, D. F. SISVAR: um programa para análises e ensino de estatística. Revista

Científica Symposium, v.6, n.1, p.36-41, 2008.

GAUTIER-HION, A. Interactions among fruit and vertebrate fruit-eaters in an African tropical rain forest. In: BAWA, K. S.; HADLEY, M. (Ed.).

Reproductive ecology of tropical forest plants. Paris: The Partenon Group, 1990. p.219-230.

GROMBONE-GUARANTINI, M. T.; RODRIGUES, R. $\mathrm{R}$. Seed bank and seed rain in a seasonal semideciduous Forest in south-eastern Brazil. Journal of Tropical Ecology, v.18, n.5, p.759-774, 2002.

HAMMER, Ø.; HARPER, D.A.T.; RYAN, P.D. PAST: Paleontological statistics software package for education and data analysis.

Palaeontologia Electronica, v.4, n.1, 2001. Disponível em: < http://palaeo electronica.org/ 2001_1/past/issue1_01.htm>
HOWE, H. F.; SMALLWOOD, J. Ecology of seed dispersal. Annual Review of Ecology and Systematics, v.13, p.201-228, 1982.

INSTITUTO NACIONAL DE METEOROLOGIA INMET. Temperaturas Diárias (Máxima, Média, Mínima). Disponível em: http:// www.inmet.gov.br/sim/gera_graficos.php. Acessado em 08 de maio de 2014.

JESUS, F. M. et al. The importance of landscape structure for seed dispersal in rain forest fragments. Journal of Vegetation Science, v.23, n.6, p.1126-1136, 2012.

LAGOS, M. C. C.; MARIMON, B. S. Chuva de sementes em uma floresta de galeria no Parque do Bacaba, em Nova Xavantina, Mato Grosso, Brasil. Revista Árvore, v.36, n.2, p.311-320, 2012.

LEITÃO FILHO, H. F. A vegetação. In: LEITÃO FILHO, H. F.; MORELLATO, L. P. (Ed.).

Ecologia e preservação de uma

floresta tropical urbana - Reserva de Santa Genebra. Campinas: UNICAMP, 1995. p.19-29.

MARIMON, B. S.; FELFILI, J. M. Chuva de sementes em uma floresta monodominante de Brosimum rubescens Taub. em uma floresta mista adjacente no Vale do Araguaia, MT, Brasil. Acta Botanica Brasilica, v.20, n.2, p.423-432, 2006.

MELO, F. P. L. et al. Forest fragmentation reduces recruitment of large-seeded tree species in a semideciduous tropical forest of southern Mexico. Journal of Tropical Ecology, v.26, n.1, p.35-43, 2010.

MUELLER-DOMBOIS, D.; ELLENBERG, H. Aims and methods of vegetation ecology. New York: John Wiley, 1974.

PENHALBER, E. F.; MANTOVANI, W. Floração e chuva de sementes em mata secundária em São Paulo, SP. Revista Brasileira de Botânica, v.20, n.2, p.205-220, 1997.

PIVELLO, V. R. et al. Chuva de sementes em fragmentos de Floresta Atlântica (São Paulo, SP, Brasil), sob diferentes situações de conectividade, estrutura florestal e proximidade da borda. Acta Botânica Brasílica, v.20, n.4, p.845-859, 2006.

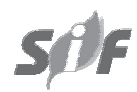

Revista Árvore, Viçosa-MG, v.38, n.4, p.689-698, 2014 
RAMIREZ, N. Produccion y costo de frutos y semillas entre formas de vida. Biotropica, v.25, n.1, p.46-60, 1993.

REIS, A.; BECHARA, F. C.; TRES, D. R. Nucleation in tropical ecological restoration. Scientia Agricola. v.67, n.2, p.244-250, 2010.

REIS, A.; ZAMBONIM, R. M.; NAKAZONO; E. M. Recuperação de áreas florestais degradadas utilizando a sucessão e as interações planta-animal. Série Cadernos da Reserva da Biosfera da Mata Atlântica, v.14, p.1-42, 1999.

SEMA MT. Sistema integrado de monitoramento e licenciamento ambiental (SIMLAM). Cuiabá: SEMA-MT, 2012. Disponível em: <http:// monitoramento.sema.mt.gov.br/simlam>Acessado em 09 de out. de 2012.

SEPLAN. Mapa de solos do Estado de Mato Grosso. Zoneamento sócio-econômico ecológico. Prodeagro, 2001.
STEFANELLO, D.; FERNANDES-BULHÃO, C.; MARTINS, S. V. Síndromes de dispersão de sementes em três trechos de vegetação ciliar (nascente, meio e foz) ao longo do rio Pindaíba, MT. Revista Árvore, v.33, n.6, p.1051-1061, 2009.

TABARELLI, M.; PERES, C. A. Abiotic and vertebrate seed dispersal in the Brazilian Atlantic forest: implications for forest regeneration.

Biological Conservation, v.106, n.2, p.165176, 2002.

URIARTE, M. et al. Disentangling the drivers of reduced longdistance seed dispersal by birds in an experimentally fragmented landscape. Ecology, v.92, n.4, p.924-937, 2011.

VIEIRA, D.C.M.; GANDOLFI, S. Chuva de sementes e regeneração natural sob três espécies arbóreas em uma floresta em processo de restauração. Revista Brasileira de Botânica, v.29, n.4, p.541-554, 2006. 